\title{
Greetings for publishing the special edition of the BIOPHILIA journal
}

\author{
Hideo Kijima, MD. PHD ${ }^{1,2}$ \\ ${ }^{1}$ Honorary president of the Japanese Biophilia Rehabilitation Academy \\ ${ }^{2}$ Yamauchi Ryuma foundation Yamauchi Hospital.
}

I served as the first president at the time of Biophilia Rehabilitation Academy establishment, which had been called the 21 st century rehabilitation study group till then. The assumption of the president greeting at the time of Academy establishment, I expressed "I expected much more research efforts of member in order to realize from "care and dependence to independence" and "elderly requiring nursing care generating to be a little less than 10\% from 16\% in 2025 assumed". I am pleased with the situation and activity where the Academy is continuing the activity which turned its eyes not only to domestic but also to the world as the same in expectation.

It was the center for me taking office as the president of this Academy that "I watch efforts of Prof. Takizawa and his associates to abolish bedridden and the result to be obtained by their efforts." He was a youth lawmaker of Fujisawa expected much to attain greatness as a politician. He had been a person of great insight of the aged society and had had a broad outlook. Therefore He noticed the peculiarity of the result of kinetic training and the technique that nobody had noticed and the rationality that enabled it to methodize. $\mathrm{He}$ relinquished a city lawmaker position to successors and didn't accept the candidacy request of the outgoing prefectural assembly chairman that had meant to be a lawmaker of the House of Representatives and dealt with the study.

He started this international activity as a sectional meeting of the domestic Academy and served as a chairperson of it. Furthermore, it is unexpected joy for me to reorganize into an independent organization under the agreement of all members of the domestic Academy and to continue activity as a president of the board of directors of the International Biophilia Rehabilitation Academy.

He has been trying to make a methodized rehabilitation of his mother, Ms. Kyoko Takizawa (RPT) performing systematize and socialize for many years. It has been 20 years since the day he had told me "I wish I was a doctor for actualizing it much faster" and I had offered him helping to do it. Though the group with physical therapist joining had shown successful result, he might know that the fact, which no doctors participated, showed it being an individual experience. Towards paper adoption, I consult with Dr. dear departed Shiro Kanai, the president of the board of directors of the Japanese Clinical Orthopaedic Association, introduced him to some national clinical orthopedists and made him explain the reality to them. It is not forgotten to have announced the article afterward. This article that was obtained and announced by many members' cooperation of the Fujisawa Clinical Orthopedists' meeting became the foundation which progressed to the Academy.

At the time of reorganization to the Academy, There was a doctor who had consented an inspector readily and the other physician who proposed studying the reproduction of the neurotransmission mechanism using an embryonic stem cell. His advocated opinion that advanced age disabled person's independence prevents the social disruption accompanying baby boomers' aging became important with a change of a time and is common recognition in intellectuals.

Although the research proposal of nerve mechanism reproduction was irrealizable, I hear that the cerebral function reconstruction from molecular genetics has been an important subject as a future focus of the Academy which works in the world. Japanese collected papers are reorganized towards PubMed registration this time, and our knowledge will be offered to the reader in the world. That our previous research has not been mediocritized yet shows the difficulty of the rehabilitation medicine restructuring.

By collecting wisdom widely with the readers' research participation, I expect that the Takizawa rehabilitation method becomes a core of rehabilitation medical treatment and will be spread, which is easy to enforce and enable to obtain the high treatment effect. 